\title{
Perception of Breast Health amongst Malaysian Female Adolescents
}

\author{
Chong Chin Che*, Jeya Devi Coomarasamy, Balakrishnan Suppayah
}

\begin{abstract}
Background: Breast cancer is the most common cancer among women in Malaysia, about one in 19 women being at risk. This study aimed to investigate knowledge and practice of breast self-examination (BSE), as well as knowledge of risk factors for breast cancer amongst female adolescents in Malaysia. Subsequently, relationships between demographic characteristics and knowledge level of BSE, risk factors for breast cancer and BSE practice were assessed. Materials and Methods: A descriptive, cross sectional survey was conducted using a sample of 500 Malaysian adolescents from the age of 15 to 19 years. A self-administered questionnaire was used to gather sociodemographic characteristics, knowledge of BSE, knowledge of risk factors for breast cancer and BSE practices. Results: The findings of this study indicated that female adolescents in Malaysia demonstrated an inadequate knowledge level of BSE and risk factors for breast cancer. Only $\mathbf{2 7 . 8 \%}$ of female adolescents performed BSE regularly. BSE practice, knowledge of BSE and knowledge of risk factors for breast cancer showed significant positive relationships. Conclusions: The study highlighted the importance of planning and implementing breast health education programs for female students in secondary schools in Malaysia. It will also provide the health care providers an avenue to stress on the importance of imparting breast health education to adolescents.
\end{abstract}

Keywords: Breast cancer - female adolescents - breast self-examination (BSE) - Malaysia

Asian Pac J Cancer Prev, 15 (17), 7175-7180

\section{Introduction}

Breast cancer is the most common cancer in women worldwide. About 1 in 8 women in the United States will develop invasive breast cancer during their lifetime (American Cancer Society, 2011). In Asia, the incidence rate of breast cancer among females is highest in Taiwan, Singapore and Philippines (McDonald et al., 2008). Breast cancer is the most common cancer among women in Malaysia regardless of ethnic groups and from the age of 15 years onwards. About one in 19 women in Malaysia are at risk (Wahid, 2007). The incidence of breast cancer is highest among Chinese followed by Indian and Malay (National Cancer Registry, 2007).

To provide evidence based recommendations for optimal care of women with breast cancer and women at risk of breast cancer, a Clinical Practice Guideline (CPG) has been developed (Academy of Medicine Malaysia, 2010). This CPG recommends mammography to be performed biennially in women from 50-74 years of age. Women aged 40-49 years should not be denied mammography screening if they desire to do so. Screening women at high risk for breast cancer should be done from the age of 30 years with both magnetic resonance imaging and mammography as it is more effective than mammography alone. Breast self-examination (BSE) is recommended for raising awareness among women at risk rather than as a screening method. Mammogram Subsidy Program was launched by the government on December 2007 to promote early detection of breast cancer. The mammogram tests were made available free of charge for women aged 40-69 years with household income of less than RM5,000 and a subsidy of RM50 for women with household income of more than RM5,000.

Adolescence is characterized by rapid change, when events and experiences have significant implications and consequences for later life. The health, knowledge, attitudes and practices of adolescents are regarded as essential factors when predicting the process of epidemiological transition of a population. The current lifestyles of adolescents are crucial for the health and disease patterns that will be observed in the future.

Based on population distribution and basic demographic characteristics by Department of Statistics Malaysia (2010), there are 2.8 million adolescents of ages between 15 and 19 years. This is about $10 \%$ of the total population. It is thus important to know what are the health risks of this large group of the population and to identify the health education needs in order to develop disease preventive strategies. Even though breast cancer among adolescence is very rare, but there are still 6 cases reported by National Cancer Registry (2007). 
Introduction of health education about breast health awareness amongst school children has been recognised for more than a decade in developed country (Rogers et al., 2002). Structured breast health education module specifically targeted on adolescents in school is scarce within the Malaysian context.

National Cancer Registry revealed there were 3,242 female breast cancer cases diagnosed in 2007 and this is $32.1 \%$ of all female cancer cases. Of the cancer cases detected, approximately $50 \%$ to $60 \%$ were at stage 3 or 4 , while only $5.2 \%$ were diagnosed at screening mammogram (Hisham and Yip, 2004). Cure rates for stage I and II cases may be as high as $80 \%$ and above (Wahid, 2007). Thus, it is important to detect breast cancer and get treatment at early stages. The delay in the detection of breast cancer is attributed to a strong belief in traditional medicine, the negative perception of the disease, poverty and poor education, coupled with fear and denial. The strong negative social and cultural perception of breast cancer in developing countries continues to be the main reason for the delay in detection (Rashidi and Rajaram, 2000).

A comprehensive review revealed a plethora of research concerning knowledge and awareness of breast cancer among Malaysian women. The studies were conducted in Selangor, Shah Alam, Penang, Kedah, Terengganu and Kuala Lumpur. However, there are no studies targeted on adolescents. Most of the participants were female teachers, female staff and students in Universities and female factory workers.

Literature revealed the majority of Malaysian women demonstrated inadequate knowledge about breast cancer and the studies showed breast self-examination practice has a significant relationship with breast cancer knowledge (Parsa et al., 2008; Abdul Hadi et al., 2010; Abdul Hadi et al., 2010; Nik Rosmawati et al., 2010; Parsa et al., 2010; Akhtari-Zavare et al., 2011; Al-Dubai et al., 2011; Kanaga et al 2011; Nor Afiah et al., 2011; Rafi Baig et al., 2011). The poor level of knowledge and lack of awareness about the screening tests can partly explain the delay in presentation of symptomatic breast cancer to health care provider (Abdul Hadi et al., 2010).

A Mini literature review by Parsa et al. (2006) showed barriers for breast cancer screening among Asian women are mainly due to the social cultural perception of the disease, poverty and the strong influence of traditional medicine. Most of the papers from Malaysia were focused on the knowledge level. Parsa et al. (2008) found there was no significant difference in knowledge in relation to age, religion, ethnic group, marital status, educational level, family history of breast cancer, and regular visits with physicians. However the studies by Abdul Hadi et al. (2010) and Al-Dubai et al. (2011) revealed significant predictors of breast cancer knowledge were age, race, level of education, occupation and employments status.

The purposes of this study were to investigate knowledge and practice of breast self-examination (BSE), knowledge of risk factors for breast cancer amongst female adolescents in Malaysia. Furthermore to explore the relationship between demographic characteristics and knowledge level of BSE and risk factors for breast cancer.

\section{Materials and Methods}

A descriptive cross-sectional study was conducted from March to June 2013. The study was conducted in two colleges in South Malaysia, three secondary schools and one university in Kuala Lumpur. The study population included female adolescents aged 15 to 19 . Convenient sampling is used to collect data from 500 female adolescents.

The research project was granted by research center of the University. The University Institutional Review Board approved the protocol. Permissions were obtained from school principals, head of colleges and dean of university faculty. Informed consent from parent and assent from the female adolescents below 18 years old were obtained. Written consent was obtained from female adolescent who are 18 years above.

A self-designed questionnaire was used for data collection. Content validity of the questionnaire was reviewed by a panel of medical and nursing lecturer from the Faculty of Medicine and Health Sciences. The instrument was then translated to Malay Language and reviewed by lecturers from university language center. The questionnaire was pilot tested among twenty university students. Reliability analysis was done with a Guttman's split Lambda 4 and shown value of 0.82 (0.7-0.9 reliable).

A self-administered questionnaire consisting of four parts were constructed for the study: socio- demographic characteristics, knowledge of breast self-examination, knowledge of risk factors for breast cancer and breast self-examination practice.

\section{Socio- demographic characteristics}

Socio-demographic data elicited from students included their age, ethnic group, school grade and family history of breast cancer.

\section{Knowledge of breast self-examination}

Knowledge of BSE was assessed with five questions. The questions were included knowledge of breast cancer; breast self-examination; the time, frequency and techniques of BSE. Source of information about breast cancer and BSE were stated and asked to choose, which are media, health professionals, book or journal, school teacher, internets and open question for "Other".

\section{Knowledge of risk factors for breast cancer}

Knowledge of risk factors for breast cancer was assessed with 16 questions. This part assessed the presence of breast cancer risk factors with reference to the guidelines of the American Cancer Society (2011).

\section{Breast self-examination practice}

The participants were asked whether they performed BSE regularly. The participant has to state the reasons for not doing BSE regularly.

\section{Data analysis}

All data were analyzed using the Statistical Package for the Social Science (SPSS) for Windows, version 21.0. One- way ANOVA was used to examine significant 
differences in knowledge level of breast self-examination, knowledge level of risk factors for breast cancer and breast self-examination practice level within sub-categories of each of the demographic variables. Correlational analysis between knowledge level of breast self-examination, knowledge level of risk factors for breast cancer and breast self-examination practice were measured using Pearson Correlation.

\section{Results}

Socio- demographic characteristics

The majority age groups of participants were 19 years (46.6\%) and 17 years (27.8\%). Most participants were Chinese $(40.8 \%)$ and Malay $(36.8 \%)$. A total of $40.2 \%$ respondents were study in colleges and universities. The majority of participants were having no family history of breast cancer (Table 1).

\section{Knowledge level of breast self-examination}

Knowledge level of breast self-examination was examined and tabulated (Table 2). Majority of Malaysian female adolescents are aware of breast cancer $(87.6 \%)$ and aware about BSE $(60.6 \%)$. But, the overall knowledge level for breast self-examination is poor $(40.4 \%)$. Female adolescents in Malaysia obtained their knowledge of breast cancer and BSE mainly from media (25\%) and internet $(22 \%)$. In contrast, there was only $14 \%$ of participants get the information from health professional.

\section{Knowledge level of risk factors for breast cancer}

Knowledge level of risk factors for breast cancer amongst female adolescents is poor (45\%). As shown in Table 3, the most widely known risk factors by the students were family history of breast cancer $(87 \%)$ and personal history of breast cancer $(68.6 \%)$. Recent oral contraceptive use (14.4\%) and deficiency of physical activity (19.6\%) were least known as a risk factor for breast cancer by most of the female adolescents.

\section{Breast self-examination practice}

The percentage of the participants who performed BSE regularly was $27.8 \%$. The most common reasons for not doing BSE were "not knowing how to perform BSE" (44.4\%), "not having family history" (29.6\%) and "not knowing the frequency of BSE " $(26 \%)$.

Relationship between demographic characteristics: age, ethnic group, school grade, family history of breast cancer and knowledge level of BSE

There were significant differences in mean knowledge scores of BSE for each of the demographic characteristics for female adolescents in Malaysia. Table 1 shown participants aged $19(2.54 \pm 0.74)$ were demonstrated the highest knowledge level of BSE compared with the other age group. Other ethnic group $(2.32 \pm 0.81)$ (Punjabi, international students, aboriginal) had the higher knowledge level of BSE when compared with Malay, Chinese and Indian. The Chinese had the lowest mean scores (1.63 \pm 0.77$)$. Adolescents with higher school grades had better mean knowledge scores of BSE. Participants who had family history of breast cancer had higher mean knowledge scores. Analysis of variance revealed significant differences in these scores.

Relationship between demographic variables: age, ethnic group, school grade, family history of breast cancer and knowledge level of risk factors for breast cancer

There were significant differences in mean knowledge scores of risk factors for breast cancer for each of the

Table 1. Demographic Characteristics and Mean Knowledge of Breast Self-Examination (BSE) $(\mathbf{n}=\mathbf{5 0 0})$

\begin{tabular}{|c|c|c|c|c|c|}
\hline Characteristics & $\mathrm{n}(\%)$ & Mean & $\mathrm{SD}$ & $\begin{array}{c}\mathrm{t} / \mathrm{F} \\
\text { statistic* }\end{array}$ & $\mathrm{p}$ value \\
\hline \multicolumn{6}{|l|}{ Age (yrs) } \\
\hline 15 & $41 \quad(8.2)$ & 1.27 & 0.45 & & \\
\hline 16 & $29 \quad(5.8)$ & 1.31 & 0.6 & & \\
\hline 17 & $139(27.8)$ & 1.48 & 0.59 & 87.51 & 0 \\
\hline 18 & $58(11.6)$ & 1.47 & 0.68 & & \\
\hline 19 & $233(46.6)$ & 2.54 & 0.74 & & \\
\hline \multicolumn{6}{|l|}{ Ethnic group } \\
\hline Malay & $184(36.8)$ & 2.27 & 0.86 & & \\
\hline Chinese & $204(40.8)$ & 1.63 & 0.77 & 23.08 & 0 \\
\hline Indian & $74(14.8)$ & 1.82 & 0.83 & & \\
\hline Other1 & 38 (7.6) & 2.32 & 0.81 & & \\
\hline \multicolumn{6}{|l|}{ School Grade } \\
\hline Form 3 & $40 \quad(8.0)$ & 1.25 & 0.44 & & \\
\hline Form 4 & $25 \quad(5.0)$ & 1.36 & 0.64 & & \\
\hline Form 5 & $169(33.8)$ & 1.62 & 0.71 & & \\
\hline Form 6 (Lower 6) & 18 (3.6) & 1.67 & 0.84 & 38.27 & 0 \\
\hline Form 6 (Upper 6) & 21 & 1.76 & 0.89 & & \\
\hline Matriculation/A level & $26(5.2)$ & 1.54 & 0.65 & & \\
\hline College/University & $201(40.2)$ & 2.52 & 0.76 & & \\
\hline \multicolumn{6}{|l|}{ Family history } \\
\hline Yes & 37 (7.4) & 2.35 & 0.75 & -2.99 & 0.003 \\
\hline No & 463 (92.6) & 1.91 & 0.87 & & \\
\hline
\end{tabular}

*Significance of difference in means between categories of each variable tested using one way ANOVA or independent sample t-test at the 0.05 level; ' 'Other' defined as Punjabi, Aboriginal, international students

Table 2. Knowledge Level of Breast Self-Examination (BSE) $(\mathbf{n}=\mathbf{5 0 0})$

\begin{tabular}{lcccc}
\hline Knowledge level of BSE & Scores & $\mathrm{n}(\%)$ & Mean & SD \\
\hline Poor & $<2$ & $202(40.4)$ & 0.01 & 0.09 \\
Moderate & $2 \sim 3$ & $124(24.8)$ & 0.15 & 0.35 \\
Good & $4 \sim 5$ & $174(34.8)$ & 0.68 & 0.47 \\
\hline
\end{tabular}

Table 3. Knowledge of Risk Factors for Breast Cancer $(\mathbf{n}=\mathbf{5 0 0})$

\begin{tabular}{lc}
\hline Risk Factors & $\mathrm{n}(\%)$ \\
\hline Family history of breast cancer & $435(87.0)$ \\
Personal history of breast cancer & $343(68.6)$ \\
High-dose radiation to chest & $261(52.2)$ \\
Never breastfed a child & $202(40.4)$ \\
Tobacco smoke & $186(37.2)$ \\
Obesity (postmenopausal) & $181(36.2)$ \\
Alcohol & $150(30.0)$ \\
Recent and long-term use of hormone replacement therapy & $142(28.4)$ \\
High fat diet & $141(28.2)$ \\
Aging & $134(26.8)$ \\
Late menopause (> 55 years) & $129(25.8)$ \\
Environmental pollution & $124(24.8)$ \\
Late age at first full-term pregnancy $(>30$ years) & $112(22.4)$ \\
Deficiency of physical activity & $98(19.60)$ \\
Early menarche $(<12$ years) & $92(18.4)$ \\
Recent oral contraceptive use & $72(14.4)$ \\
\hline
\end{tabular}


demographic characteristics for female adolescents in Malaysia. The same trend as for knowledge level of BSE was apparent, aged 19, others ethnic group and college or university students had higher knowledge level of risk factors for breast cancer. However, family history of breast cancer did not indicate statistically significant.

Relationship between demographic variables: age, ethnic group, school grade, family history of breast cancer and breast self-examination practice

The data was examined for any significant difference in BSE practice according to participant demographics characteristics. Analysis of variance indicated statistically significant differences between age, ethnic group and school grade except family history of breast cancer.

Relationship between knowledge level of BSE, knowledge level of risk factors for breast cancer and breast selfexamination practice

Finally the relationship between knowledge level of BSE, knowledge level of risk factors for breast cancer and breast self-examination practice were analysed by using Pearson Correlation. All BSE practice, knowledge of BSE and knowledge of risk factors for breast cancer shows significant positive relationship, but BSE practice and knowledge of BSE indicate a higher positive linear correlation ( $\mathrm{p}=0.644)$. There is a positive linear correlation between knowledge of BSE and knowledge of risk factors for breast cancer $(\mathrm{p}=0.411)$.

\section{Discussion}

The main finding of this study indicated that female adolescents in Malaysia demonstrated an inadequate knowledge level of BSE and risk factors for breast cancer, as well as BSE practice. Findings from this present study are generally consistent with the local studies (Abdul Hadi et al., 2010; Akhtari-Zavare et al., 2011; Redhwan et al., 2011). These studies were conducted amongst local female university students. Similar findings were shown in Turkey (Karayurt et al., 2008) and Angola (Sambanje, 2012).

Significant predictors of BSE knowledge were age, ethnic group, school grade and family history of breast cancer. Better knowledge level of BSE is seen as the age progress. It could be attributed to a better level of education and much wider exposure to breast health information. Amongst the ethnic group, Malays demonstrated the highest knowledge level. This could be attributed to the distribution of the population in this study were more Malays in colleges and universities setting. Family history of breast cancer has been identified as a strong predictor of BSE knowledge ( $\operatorname{sig}=0.003)$, it could be due to the individual's involvement directly or indirectly in the caring process of the family member with the illness. The study finding of source of information is indicating media and internet are the main sources, which is congruent with similar finding from McMenamin et al. (2005) and Nor Afiah et al. (2011).

However the involvement of health professionals in providing information of breast cancer and BSE is not significant and this is a major concern which needs to be addressed. BSE is a complex skill or process to be learned by the late adolescents. It involved knowledge and motor skills development. According to Clark (2003), the teaching strategy chosen should contribute to total learning, not just knowledge acquisition. And the strategy should foster learner participation in the encounter. The appropriate teaching strategy is demonstration and followed by a return demonstration. Therefore, healthcare professional, such as nurses are the most appropriate person in teaching BSE. Half of the participants (52.2\%) acquired information from school teacher, which is a fairly good finding. However the information provided by teachers might be theoretical and not technical as in mastering the technique of BSE. Hence, it is recommended collaboration effort between school and health professionals must be initiated using smart partnership approaches.

It was encouraging to know that the majority of the participants were able to identify family history and personal history as important risk factors for breast cancer. However, the participants' knowledge level on risk factors for breast cancer is generally poor (45\%). Comparing between modifiable and non-modifiable risk factors of breast cancer, it was noted that knowledge level on modifiable risk factors is lower. The findings is consistent with International Health Behaviour Survey which was carried out in 23 countries (included USA, Europe, Asia, Africa and South America) revealed knowledge of risk factors for breast cancer was poor, particularly related to lifestyle risk factors (Peacey et al., 2006). This is an important finding in this study because any efforts or measures to minimize the incidence of breast cancer among Malaysian women, it needed to be directed on health education activities related to these modifiable risk factors.

There were $27.8 \%$ of female adolescents performed BSE regularly, the findings was lower than university students (Akhtari-Zavare et al., 2011; Redhwan et al., 2011). This study shows a positive relationship between knowledge level of BSE, knowledge level of risk factors for breast cancer and breast self-examination practice. It is a very significant finding from this study, in order to promote BSE practice, it is crucial to increase the knowledge level of breast cancer, knowledge level of BSE and knowledge level of risk factors for breast cancer.

The incidence rate and prevalence of breast cancer in Malaysia is significantly high. The mortality and morbidity rates of the illness also remain high mainly because patients present with advanced disease (Hisham and Yip, 2004). The results indicate that the awareness of breast cancer and practice of BSE are inadequate among the population. Progressive decline in mortality rate for breast cancer in United States was attributed to several factors including emphasis on early detection and education of professionals and public (Vogel, 2000). Therefore, effective breast health education programs especially amongst adolescents can certainly contribute positively in reducing the above mentioned rates. There is a need to introduce breast cancer education on risk factors, signs and symptoms, screening methods of breast cancer focus on female adolescents.

The teenage years are the pivotal point for the 
development of personal skills for adult survival. The most important elements in developing personal skills are to educate adolescents on matters related to their health and to support them in changing (McMurray, 2005). Health promotion should be offered in a setting that is most conducive to change, school is a major influence on whether or not adolescents feel free to question and learn. Opportunities must be provided in the formal education system for safe and guided discussions. Breast health education programs amongst adolescents in schools should be made a national priority. Study showed many young people have misconceptions and fears about cancer and strongly recommends that cancer education needs to adopt a whole school approach which is incorporated in teaching curriculum and collaborate with local community (Charlton, 1994; Rogers et al, 2002). Therefore, a structured program incorporating both the knowledge and skills component should be introduced in the schools. Cooperation and understanding between the Ministry of Education and Ministry of Health need to be strengthened for the successful implementation of these programs.

The role and contributions of non-government organizations' (NGO) can neither be ignored nor denied. NGO's should be encouraged to participate with the government agencies in promoting breast health activities.

Also the role of mass media should be further emphasized as it was found to play a key role in imparting breast health education. Internet usage amongst late adolescents is relatively high, it is $14.2 \%$ internet user are in this age group (Malaysian Communications and multimedia Commission, 2012). Therefore, breast health information is highly recommended to disseminate through internet or social network .These measures can result in a more positive attitude towards preventive health care.

Few limitation have been identified from this study, firstly the adoption of convenient sampling in this study has limited representation of the entire population. Furthermore, quantitative research may not able to explore subjective aspects of breast health issues. Qualitative studies on barriers of breast health awareness in Malaysia are strongly recommended. In order to maximizing the effectiveness and efficiency of community based health education project, it is essential for a health care professional team to have a good understanding of the problems.

In conclusion, research on breast cancer awareness among adolescents in Malaysia is still new, and more similar studies are recommended. The findings from this study indicate the need for healthcare professionals to strengthen their role in promoting breast cancer awareness. The study has also highlighted the importance of planning and implementing breast health education programs for female students in secondary schools in Malaysia.

\section{Acknowledgements}

The study was supported by Centre of Excellence for Research, Value Innovation and Entrepreneurship, UCSI University. The authors would like to thank the school principals, head of colleges and dean of university faculty whom granted approval for this study to conduct in their institutions. Sincere thanks and appreciation also extended to all the participants.

\section{References}

Abdul Hadi M, Hassali MA, Shafie AA, et al (2010). Evaluation of breast cancer awareness among female university students in Malaysia. Pharm Pract, 8, 29-34.

Abdul Hadi M, Hassali MA, Shafie AA, et al (2010). Knowledge and perception of breast cancer among women of various ethnic groups in the state of Penang: A cross-sectional survey. Med Princ Pract, 19, 61-7.

Academy of Medicine Malaysia (2010). Clinical practice guideline for breast cancer: Management of breast cancer. 2nd ed. Kuala Lumpur: Ministry of Health Malaysia,

Al-Dubai SAR, Qureshi AM, Saif-Ali R, et al (2011). Awareness and knowledge of breast cancer and mammography among a group of Malaysian women in Shah Alam. Asian Pac $J$ Cancer Prev, 12, 2531-8.

Akhtari-Zavare M, Juni MH, Rosliza AM, et al (2011). Knowledge on breast cancer and practice of BSE among selected female university students in Malaysia. Med Health Sci J, 7, 49-56.

American Cancer Society (2011). Cancer facts and figures 2012.

Charlton A (1994). Cancer and health promotion in schools. Health Educ J, 53, 214-21.

Clark MJ (2003). Nursing in the community. 2nd ed. New Jersey: Prentice Hall. Department of Statistics Malaysia (2010). Population distribution and basic demographic

Characteristics [Online], Available: http://www.statistics. gov.my/portal/download_Population/files/census2010/ Taburan_Penduduk_dan_Ciri-ciri_Asas_Demografi.pdf. [2013, March 3].

Hisham A, Yip CH (2004). Overview of breast cancer in Malaysian women: A problem with late diagnosis. Asian $J$ Surg, 27, 130-3.

Kanaga KC, Nithiya J, Noor Shatirah MFV (2011). Awareness of breast cancer and screening procedures among Malaysian women. Asian Pac J Cancer Prev, 12, 1965-7.

Karayurt O, Ozmen D, Cetinkaya AC (2008). Awareness of breast cancer risk factors and practice of breast self examination among high school students in Turkey. Asian Pac J Cancer Prev, 12, 3063-8.

Malaysian Communications and multimedia Commission (2012). Statistical Brief Number fifteen internet users survey.

McDonald M, Hertz RP, Pitman Lowenthal SW (2008). Pfizer facts: The burden of cancer in Asia.

McMenamin M, Barry H, Lennon AM, et al (2005). Irish National Cancer/Cardiac Awareness (INCA) survey. Eur J Cancer, 41, 393-7.

McMurray A (2005). Community health and wellness: A socioecological approach. Sydney: Mosby Elsevier.

National Cancer Registry (2007). National Cancer Registry Report: Malaysia Cancer Statistic Data and Figure.

Nik Rosmawati NH (2010). Knowledge, attitude and practice of breast self-examination among women in a suburban area in Terengganu, Malaysia. Asian Pac J Cancer Prev, 11, 1503-8.

Nor Afiah MZ, Hejar AR, Looi YK, et al (2011). Breast cancer screening: How knowledgeable are female staffs of a public university? Int Med J Malays, 10, 23-9.

Parsa P, Kandiah M, Abdul Rahman H, et al (2006). Barriers for breast cancer screening among asian women: A mini literature review. Asian Pac J Cancer Prev, 7, 509-14.

Parsa P, Kandiah M, Nor Afiah MZ, et al (2008). Knowledge and behavior regarding breast cancer screening among female teachers in Selangor, Malaysia. Asian Pac J Cancer 


\section{Chong Chin Che et al}

Prev, 9, 221-2.

Parsa P, Kandiah M (2010). Predictors of adherence to clinical breast examination and mammography screening among Malaysian women. Asian Pac J Cancer Prev, 11, 681-8.

Peacey V, Steptoe A, Sigurlı́na D, et al (2006). Low levels of breast cancer risk awareness in young women: An international survey. Eur J Cancer. 42, 2585-9.

Rafi Baig M, Subramaniam V, Chandrasegar AA, et al (2011). A population based survey on knowledge and awareness of breast cancer in the suburban females of Sungai Petani, Kedah, Malaysia. Int J Collab Res Intern Med Public Health. 3, 671-9.

Rashidi A, Rajaram SS (2000). Middle Eastern Asian Islamic women and breast self-examination. Needs assessment. Cancer Nurs, 23, 64-70.

Redhwan AA, Dhekra HA, Yuri VB, et al (2011). Practice and barriers towards breast self-examination among young Malaysian women. Asian Pac J Cancer Prev, 12, 1173-8.

Rogers C, Thompson K, Robinson S (2002). Introducing a breast health strategy into schools. Health Educ J, 102, 106-12.

Sambanje MN, Mafuvadze B (2012). Breast cancer knowledge and awareness among university students in Angola. Pan Afr Med J, 1937-88.

Vogel VG (2000). Breast cancer prevention: A review of current evidence. CA Cancer J Clin, 50, 156-70.

Wahid M (2007). Breast Cancer. Malaysian Oncological Society (2004-2007). 